\section{Gênero mulher negra: como (re)existir?}

\section{Gender black woman: how (re)exist?}

\section{Jorge Luís Rodrigues dos Santos}

https://orcid.org/0000-0002-9936-1548 Universidade Estadual de Maringá alsilva.iv@gmail.com

Tatiana Costa de Souza Pereira iD

https://orcid.org/0000-0002-4876-4400 Universidade Estadual de Maringá tkteruya@gmail.com

DOI: 10.22481/odeere.v5i10.7905

\section{RESUMO:}

O que é ser "mulher"? Como se reconhece (ou não) alguém que se identifica como mulher? Há diferenças entre mulheres? O significado da palavra mulher "do latim mulier, uma mulher é uma pessoa do sexo feminino. Trata-se de um termo que se utiliza em contraste a homem, conceito que nomeia o ser humano do sexo masculino'". A construção da mulher parece depender da existência do homem, a quem se opõe (e de quem, de acordo com a teologia judaicocristã é trazida à existência). Mulher: "pessoa do sexo feminino que já tendo chegado à sua puberdade ou à idade adulta. Por conseguinte, a menina (ou rapariga) passa a ser mulher, de acordo com os padrões culturais, a partir da sua primeira menstruação". Além do significado biológico, há também a construção do "ser mulher" em diferentes áreas do conhecimento e da cultura.

PALAVRAS-CHAVE: Gênero; Mulher Negra; Feminismo Negro; Racismo; Antirracismo.

\begin{abstract}
:
What is being a woman"? How do you recognize (or not) someone who identifies as a woman? Are there differences between women? The meaning of the word woman "from the Latin mulier, a woman is a female person. It is a term that is used in contrast to men, a concept that names the human being male". The construction of the woman seems to depend on the existence of the man, whom she opposes land whom, according to Judeo-Christian theology, is brought into existence). Woman: "female person who has already reached puberty or adulthood. Consequently, the girl (or girl) becomes a woman, according to cultural standards, from her first menstruation". In addition to the biological significance, there is also the construction of "being a woman" in different areas of knowledge and culture.
\end{abstract}

KEYWORDS: Genre; Black woman; Black Feminism; Racism; Anti-racism.

${ }^{1}$ Mulher. Extraído de: https://conceito.de/mulher 
Bem, se a mulher perturbou o mundo, dê-lhe uma chance de ajustá-lo novamente.

(Sojourner Truth2)

\section{INTRODUÇÃO}

O que é ser "mulher"? Como se reconhece (ou não) alguém que se identifica como mulher? Há diferenças entre mulheres? O significado da palavra mulher "do latim mulier, uma mulher é uma pessoa do sexo feminino. Trata-se de um termo que se utiliza em contraste a homem, conceito que nomeia o ser humano do sexo masculino3". A construção da mulher parece depender da existência do homem, a quem se opõe (e de quem, de acordo com a teologia judaico-cristã é trazida à existência). Na cultura africana, uma lenda de Moçambique, a respeito dos papéis das mulheres e dos homens, citada por Chiziane4:

No princípio de tudo, as mulheres governavam o mundo. Deus, que era uma mulher, residia no pico dos Montes Namuli. A Deusa era uma bela amorosa e também uma fera poderosa. Um dia, um homem, vindo de um lugar qualquer, descobriu, naquele paraíso original, a beleza do feminino. Seduziu a deusa com uma paixão fatal. Depois da dança do amor, eis que o homem rouba o manto real da deusa e se proclama Deus, usurpando, assim, o poder feminino e submetendo as mulheres ao seu domínio. Começou a disputa pela recuperação do manto perdido, na guerra dos sexos que dura até hoje. O manto rasgou-se ao meio e cada um ficou com a metade. Homem e mulher viraram as costas um ao outro e houve separação. Esta disputa deu-se na nascente dos rios gêmeos. È por isso que o rio Licungo, masculino, segue o caminho para a Zambézia, levando o patriarcado para o Sul. O Rio Malema, feminino, vai para Nampula, levando o matriarcado para o Norte de Moçambique e todo o continente africano.

Podemos verificar que em cada cultura, a perspectiva sobre o que é ser "homem" ou ser "mulher" possui diferentes significados, que são construídos historicamente.

Mulher: "pessoa do sexo feminino que já tendo chegado à sua puberdade ou à idade adulta. Por conseguinte, a menina (ou rapariga) passa a ser mulher, de acordo com os padrões culturais, a partir da sua primeira menstruação". Além do significado biológico, há também a construção do "ser mulher" em diferentes áreas do conhecimento e da cultura. E existir-se mulher é ter apenas uma maneira

\footnotetext{
2 TRUTH, Sojourner. Eu não sou uma mulher? E outros discursos. Belo Horizonte: Nandyala, 2019.

${ }^{3}$ Mulher. Extraído de: https://conceito.de/mulher

${ }^{4}$ Chiziane, 2018, p.17.
} 
de ser e estar no mundo? Que características compõem esta natureza? Rodrigues ${ }^{5}$ afirma que "um dos problemas da ênfase política na categoria "mulher" era sua definição por oposição a "homem", restringindo o universo sexual e social em dois gêneros, masculino e feminino, marcados por uma divisão biológica, natural, e portanto, imutável". E essa oposição ao homem promove uma suposta e "natural subalternização e inferiorização da mulher" em relação ao homem. Scott’ destaca que:

Os estudos sobre gênero efetuados nas décadas de 1970 e 1980 permitiram acrescentar novos temas aos então chamados estudos sobre a mulher e alargar os modos convencionais de fazer ciência, abrindo espaço às experiências pessoais e subjetivas das mulheres. Nessa construção, gênero foi desenvolvido como uma categoria de análise, do mesmo modo que classe social e raça, os três eixos de organização do poder na sociedade.

Rodrigues $^{7}$ observa ainda que:

Nos anos 1980, uma tentativa de pluralizar "as mulheres" pretendia dar conta da emergência de diferentes contextos de opressão feminina. Mulheres negras, brancas, ricas, pobres, ocidentais, orientais, trabalhadoras, mães, escolarizadas ou analfabetas não podiam ser estabilizadas na categoria "mulher", sob pena desta categoria tornar-se paradoxalmente aquilo que pretendia combater. Ou o referente "mulher" abria-se a possibilidades plurais, ou representaria apenas um grupo muito restrito de mulheres brancas, de classe média, de alta escolaridade, cujos anseios de emancipação não eram coerentes com as condições precárias e subalterna da vida de inúmeras outras mulheres.

O "Gênero mulher" tem sua construção cada dia mais problematizado, e em particular, o ser "mulher negra" é uma condição atravessada de violências e desigualdades, em diversas áreas e níveis da vida social. A luta das mulheres negras, além de feminista exige também que seja antirracista. A existência (e resistência) negra e feminina na contemporaneidade busca a ampliação e reconhecimento de direitos, a valorização de suas corporeidades e estéticas, a liberdade e o respeito às suas subjetividades, a conquista plena de sua humanidade. $O$ "gênero mulher negra" é um conceito que está em processo de construção, ampliação e empoderamento.

\footnotetext{
${ }^{5}$ Rodrigues, 2016.

${ }^{6}$ Scott, 1990 apud Meneghel, Farina e Ramão, 2005, p.567.

${ }^{7}$ Rodrigues, 2016.
} 


\section{IDENTIDADE NEGRA E RACISMO MIDIÁTICO.}

A emergência no cenário mundial globalizado de novas identidades (étnicas, de gênero, políticas) tem provocado à assunção de movimentos que buscam resgatar, ressignificar e empoderar estas novas identidades, que se inserem em diferentes e variados contextos econômicos, sociais, políticos, culturais, religiosos, etc. Vieira e Gomes ${ }^{8}$ destacam que "em períodos de contemporaneidade, chamados por alguns de pós-modernidade, a questão da identidade se torna componente fundamental para os processos de reivindicação política e promoção social". No Brasil, de modo particular, a identidade negra, agora majoritária demograficamente, busca uma afirmação de suas referências, nas mais diversas esferas da sociedade. Hall9 observa que:

as culturas nacionais, ao produzir sentidos sobre "a nação", sentidos com os quais podemos nos identificar, constroem identidades. Esses sentidos estão contidos nas estórias que são contadas sobre a nação, memórias que conectam seu presente com seu passado e imagens que dela são construídas. (...) a identidade nacional é uma "comunidade imaginada".

O imaginário sobre o negro ainda é marcado por estereótipos de inferioridade, incapacidade, perigo, e a maneira como são (des)tratados em virtude de sua corporeidade revela um preconceito intenso, que promove situação de exclusão aos portadores do que é considerado um defeito de cor (grifo meu). A identidade negra é considerada uma marca corporal, um defeito, que estabelece fronteiras, estigmatiza indivíduos e restringe direitos. Práticas racistas promovidas contra negros e negras ocorrem cotidianamente, e são consideradas normais. As sociedades na contemporaneidade, apesar da luta empreendida por diferentes movimentos em busca da ressignificação da identidade negra, enfrentam uma disputa ideológica, que buscam resistir e impedir a positivação do ser negro no Brasil (grifo meu). A valorização identitária exige uma postura de militância e resistência. E de acordo com Cristaldo 10 "a porta de entrada para a militância de mulheres negras contra o racismo tem sido, em muitos casos, o cuidado com a estética" (...). A respeito do conceito de estética, Almada ${ }^{11}$ afirma: Hoje, no senso comum, estética é uma palavra ligada à beleza, e

\footnotetext{
8 Vieira e Gomes, 2016, p.263.

9 Hall, 2006, p.51.

10 Cristaldo, 2016.

11 Almada, 2010, p.141.
} 
muito frequentemente, àquela que se alcança com os cuidados do corpo. Entretanto, nos meios acadêmicos e entre os filósofos que há séculos estudam o tema, estética é vista como algo mais amplo. Trata-se da "Filosofia do belo", da "ciência do belo", do "estudo do gosto", que começa na Grécia antiga e está intimamente ligada à história da arte.

Almada em seu texto registra o depoimento de Júlio César Tavares, intelectual negro e doutor em Antropologia, que observa: "a apreciação e o gosto estéticos são construídos socialmente, por isso podemos ter noções distintas do que é ou não belo". E as construções sociais variam de cultura para cultura, e são influenciadas pelo contexto histórico. Santos ${ }^{12}$ observa:

A desvalorização dos traços corpóreos, estética, práticas culturais e valores africanos e afro-brasileiros fortemente presentes na sociedade brasileira, acaba por orientar/sustentar as práticas racistas que cotidianamente são difundidas na mídia nacional. Invisibilidade, estereotipia, marginalização, são traços recorrentes dos conteúdos veiculados sobre negros/as.

Os veículos de mídia13, por sua importância e influência na sociedade global (e na brasileira em particular), poderiam atuar menos preconceituosamente na produção e veiculação de conteúdos referentes à população negra. Os modos pelos quais são enunciados os discursos, os espaços destinados a temas de interesse da população negra ou a invisibilidade ou reduzido acesso a profissionais negros nas empresas de mídia, só contribuem para a manutenção de desigualdade e exclusão da população negra. Como bem observam Tavares e Freitas ${ }^{14}$ :

"(...) Tal fato ilustra o modo como com que representações de raça e etnia determinam práticas configuradas com base nas representações veiculadas pela mídia, que contribuem para a reprodução daquela estrutura sutil de injustiça social, tão presente nos modos de ver, classificar, hierarquizar e conceituar a realidade.

De um modo geral, a mídia dominante não promove a crítica afirmativa. Simplesmente executa o mecanismo cognitivo que reitera grande parte da visão de mundo operante e dominante. Por vezes, em nome da necessária facilidade de constituir ampla audiência, simplifica o conteúdo para torná-lo palatável, assimilável e mais facilmente digerido. A simplificação não implica condensação, mas

\footnotetext{
12 Santos, 2017, p.69.

13 Mídia: Qualquer suporte de difusão de informações (rádio, televisão, imprensa escrita, livro, computador, videocassete, satélite de comunicações etc.) que constitua simultaneamente um meio de expressão e um intermediário capaz de transmitir uma mensagem a um grupo; meios de comunicação, comunicação de massa. Disponível em: http://www.dicio.com.br/midia 2/. Acesso em: 28/06/2014.
}

14 Tavares e Freitas, 2010, p.215, 216. 
"descontextualização". (...) Com isso, os veículos de comunicação reafirmam o senso comum, cristalizando no pensamento popular o que se apresenta muitas vezes incoerente, fragmentário e desarticulado, resultado da história de colonialismo, escravidão e intolerância étnica e cultural, que foram fundamentais para a criação do estado eurocêntrico brasileiro e que, ainda hoje, sustentam o preconceito, a discriminação e o racismo".

Borges ${ }^{15}$, referindo-se aos discursos veiculados na mídia brasileira a respeito dos negros e da mulher negra em particular, destaca que "olhando de soslaio para a paisagem midiática brasileira podemos observar um trajeto, pontilhado por estigmas e estereótipos, que parecem se repetir indefinidamente". A invisibilidade provocada pela memória, produz uma blindagem cognitiva que provoca uma visão distorcida da realidade social. A mídia é um instrumento de grande importância na manutenção do racismo, em virtude de sua intensa e massiva influência nas opiniões e comportamentos sociais. Porém, percebe-se que é possível, através do domínio da gramática da mídia, resistir e superar as consequências do racismo, tendo os grupos desfavorecidos que apropriar-se de modo adequado dos recursos oferecidos por ela, transformando-a assim em instrumento de luta e resistência. Neste sentido Ramos ${ }^{16}$ assevera:

Nenhum processo cultural de superação do racismo, de combate aos estereótipos e de luta contra a discriminação será realizado sem os jornais, a televisão, as artes, a música. Por essa centralidade - e a despeito de ter sido até recentemente pouco explorada pela militância anti-racista - a mídia tende a ter cada vez mais, na sociedade brasileira, um papel vital na construção de saídas capazes de reduzir a exclusão racial.

No caso do Brasil, em particular, a mídia, de acordo com Borges e Borges 17 "tem sido um território interditado às populações negras e, também, um espaço de constante criação de estereótipos". As mídias na sociedade contemporânea globalizada exercem um poder nada desprezível, que influencia as diferentes formas de relacionamento, promovendo aceitação e exclusão por meio das imagens e discursos que difunde. Discurso que, segundo van Dijk ${ }^{18}$ favorece a difusão de preconceitos e ideologias, que circulam socialmente e promovem uma

\footnotetext{
15 Borges, 2012, p.188.

16 Ramos, 2002, p.9.

17 Borges e Borges, 2012, p.36.

18 van Dijk, 2008, p.8.
} 
aprendizagem comunicativa racista. E van Djik ${ }^{19}$ destaca ainda que:

Esse processo de aprendizagem é amplamente discursivo, isto é, baseado na conversação e no contar de histórias diárias, nos livros, na literatura, no cinema, nos artigos de jornal, nos programas de TV, nos estudos científicos, entre outros. Muitas práticas de racismo cotidiano, tais como as formas de discriminação, podem até certo ponto ser aprendidas pela observação e imitação, mas até mesmo estas precisam ser explicadas, legitimadas ou sustentadas discursivamente de outro modo. Em outras palavras, a maioria dos membros dos grupos dominantes aprende a ser racista devido às formas de texto e de fala numa ampla variedade de eventos comunicativos.

E as práticas midiáticas racistas acabam por construir uma memória comunicativa que é apreendida nas interações cotidianas e reproduzidas muitas vezes de modo informal e inconsciente. Deste modo, torna-se necessário uma resistência que permita a desconstrução das práticas racistas. O que Santos 20 denomina de "memória comunicativa da negritude em diáspora". Uma memória que recupera, atualiza, as contribuições da cultura negra afro-diaspórica presentes na estrutura social e que são esquecidas ou invisibilizadas. Que promova um diálogo com conteúdos da negritude, estimule o seu reconhecimento, e por meio de uma estrutura discursiva desenvolva uma (re)construção de uma memória negra que circule na esfera social e permite a valorização e empoderamento da comunidade negra e seus valores.

Há a necessidade e importância de se utilizar de ferramentas comunicacionais e buscar a ocupação de espaços na esfera midiática; é fundamental para que se possa desconstruir a influência do racismo na comunicação social brasileira ${ }^{21}$. Promover discursos de natureza antirracista, buscando desconstruir o imaginário preconceituoso sobre a população negra. Resgatar uma memória sobre a estética e corporeidade negras, muitas vezes interditada, não verbalizada, mas presente nas práticas sociais e culturais da

\footnotetext{
19 van Djik, 2008, p.15.

20 Santos, 2017, p.166.

${ }^{21}$ Conceito de Comunicação Social. A comunicação é o processo e o resultado de comunicar: informar, dar a conhecer, transmitir sinais, ou lidar com uma pessoa através da palavra escrita ou oral. Social, por outrolado, é tudo ligado à sociedade (uma comunidade de indivíduos que compartilham tradições e costumes e têm certos objetivos em comum).

A comunicação social é o conjunto de estudos científicos que analisam tudo que está relacionado com o desenvolvimento dos processos comunicativos em uma sociedade. Disponível em: https://conceito.de/comunicacao-social Acesso em: 28/10/2019.
} 
sociedade brasileira. Memória que necessita ser resgatada, ressignificada, reconhecida, valorizada, e difundida discursiva e imageticamente, contrapondose aos discursos hegemônicos, excludentes e racistas ainda vigentes. Pereira e Gomes22 destacam:

No contexto contemporâneo, onde mil vozes se cruzam em diferentes processos de afirmação de identidade, a questão sobre a identidade dos negros brasileiros parece não se resolver mais com uma receita pronta. Antes, ela se impõe como horizontes que desafiam a capacidade de organização dos grupos sociais, bem como a perspicácia daqueles que assumem a tarefa de veicular os discursos de afirmação da identidade. Em função disso, a realidade das relações étnicas - com suas implicações políticas, econômicas e ideológicas - se apresenta também numa dimensão comunicacional, indicando que é pertinente investigar as interferências da mídia nos processos de elaboração de identidades individuais e coletivas.

O enfrentamento desta questão tem ocorrido em várias frentes, e o espaço virtual tem se transformado em um quilombo midiático, onde diferentes temas de interesse da população negra são visibilizados, veiculados, e tal fato têm promovido um e-empoderamento da identidade e estéticas negras, por meio da produção e difusão de imagens e discursos de resistência no espaço virtual. E neste sentido, Chiziane23 afirma:

hoje, nós, mulheres africanas e afrodescendentes, inauguramos uma nova etapa das nossas lutas. Hoje, podemos falar. Escrever. Sonhar. Nos nossos sonhos, escritas e falas, precisamos de resgatar o nosso passado e entregá-lo às novas gerações, para que possam usá-lo e, nele, se inspirarem para enfrentarem os desafios do futuro.

Luciana Barreto, em entrevista à Sampaio24 declara que "todo lugar onde o nosso povo está é nosso lugar também; é lugar de estarmos discutindo os nossos direitos. A comunicação empodera qualquer um, por isso precisamos nos apropriar disso e fazer com que ela seja nossa também". E Luciana observa ainda que "ela tem ferramentas que podem ser usadas para potencializar nossas lutas" (grifos meus).

\footnotetext{
22 Pereira e Gomes, 2001, p.179.

23 Chiziane, 2018, p.25.

24 SAMPAIO, Cristiane. Os meios tradicionais massacram a nossa identidade negra. Disponível em: https://www.brasildefato.com.br/2016/07/27/os-meios-tradicionais-massacram-a-nossaidentidade-negra-diz-apresentadora/
} 
VIOLÊNCIA RACIAL NO ESPAÇO VIRTUAL: NEGROS E NEGRAS NO PELOURINHO MIDIÁTICO.

A cultura da mídia ${ }^{25}$ é extremamente presente e potente na contemporaneidade. De acordo com Kellner26:

Há uma cultura veiculada pela mídia cujas imagens, sons e espetáculos ajudam a urdir o tecido da vida cotidiana, dominando o tempo de lazer, modelando opiniões políticas e comportamentos sociais, e fornecendo o material com que as pessoas forjam a sua identidade. O rádio, a televisão, o cinema e outros produtos da indústria cultural fornecem os modelos daquilo que significa ser homem ou mulher, bem-sucedido ou fracassado, poderoso ou impotente. A cultura da mídia também fornece o material com que muitas pessoas constroem seu senso de classe, de etnia e raça, de nacionalidade, de sexualidade, de "nós" e "eles". Ajuda a modelar a visão prevalecente de mundo e os valores mais profundos: define o que é considerado bom ou mão, positivo ou negativo, moral ou imoral. As narrativas e as imagens veiculadas pela mídia fornecem os símbolos, os mitos e os recursos que ajudam a constituir uma cultura comum para a maioria dos indivíduos em muitas regiões do mundo de hoje. A cultura veiculada pela mídia fornece o material que cria identidades pelas quais os indivíduos se inserem nas sociedades tecnocapitalistas contemporâneas, produzindo uma nova forma de cultura global.

Kellner27 afirma que "a cultura da mídia é um terreno de disputa no qual os grupos sociais importantes e ideologias políticas rivais lutam pelo domínio, e que os indivíduos vivenciam essas lutas por meio de imagens, discursos, mitos e espetáculos veiculados pela mídia". O espaço virtual, canal quase onipresente da sociedade contemporânea, torna-se também cotidianamente um espaço de violências e agressões. As redes sociais têm sido também utilizadas para a disseminação de discursos discriminatórios e diferentes formas de violência, muitas de cunho racista. Um verdadeiro "pelourinho28 digital contemporâneo", que os expõe de modo negativo, como se fossem criminosos, culpados, e devendo ser punidos. Diferentes formas de atitudes racistas dirigida a negros e negras, no

\footnotetext{
${ }_{25}$ Cultura da mídia. Kellner utiliza o termo "cultura da mídia", para descrever o "estudo cultural" que abranja todo o espectro da mídia e da cultura (2006, p. 52), diferenciando-o dos termos "cultura popular" e "cultura de massa" - grifos meus. O uso do termo busca "designar tanto a natureza quanto a forma das produções da indústria cultural (ou seja, a cultura) e seu modo de produção e distribuição (ou seja, tecnologias e indústrias da mídia).

26 Kellner, 2001, p.9.

27 Kellner, 2001, p.10.

28 Pelourinho: Coluna de pedra usada para castigar, localizada num local central e público, através da qual os escravos castigados e/ou criminosos eram exibidos. Disponível em:

http://www.dicio.com.br/pelourinho/ Acesso em 01/11/2019.
} 
espaço virtual, procuram desqualificar sua aparência física e corporeidade. Fonseca ${ }^{29}$ observa que

Muitos dos traços que continuam a legitimar preconceitos existentes na sociedade brasileira, ligados à cor da pele, às feições do rosto, ao tipo de cabelo e a uma gama infindável de elementos que qualificam ou desmerecem o indivíduo, têm sua origem num processo configurado pela mercantilização da escravidão, que transforma o africano em coisa, objeto de escambo ou de troca monetária.

Esta situação implica em determinar um lugar subalterno para aqueles/as que sendo identificados pelo fenótipo negro e que devem por isso submeter-se a condições de inferioridade e menos valia. A discriminação está justificada pela lógica racista. Podemos verificar tal situação em alguns episódios sofridos por mulheres negras, como as atrizes Thaís Araújo e Cris Vianna, e a jornalista Maria Julia Coutinho. Comentários agressivos, aludindo à sua cor de pele e sua presença como destaques no cenário midiático nacional (atrizes de novelas da Rede Globo, e "garota do tempo" do Jornal Nacional) bem confirmam a observação de Fonseca.

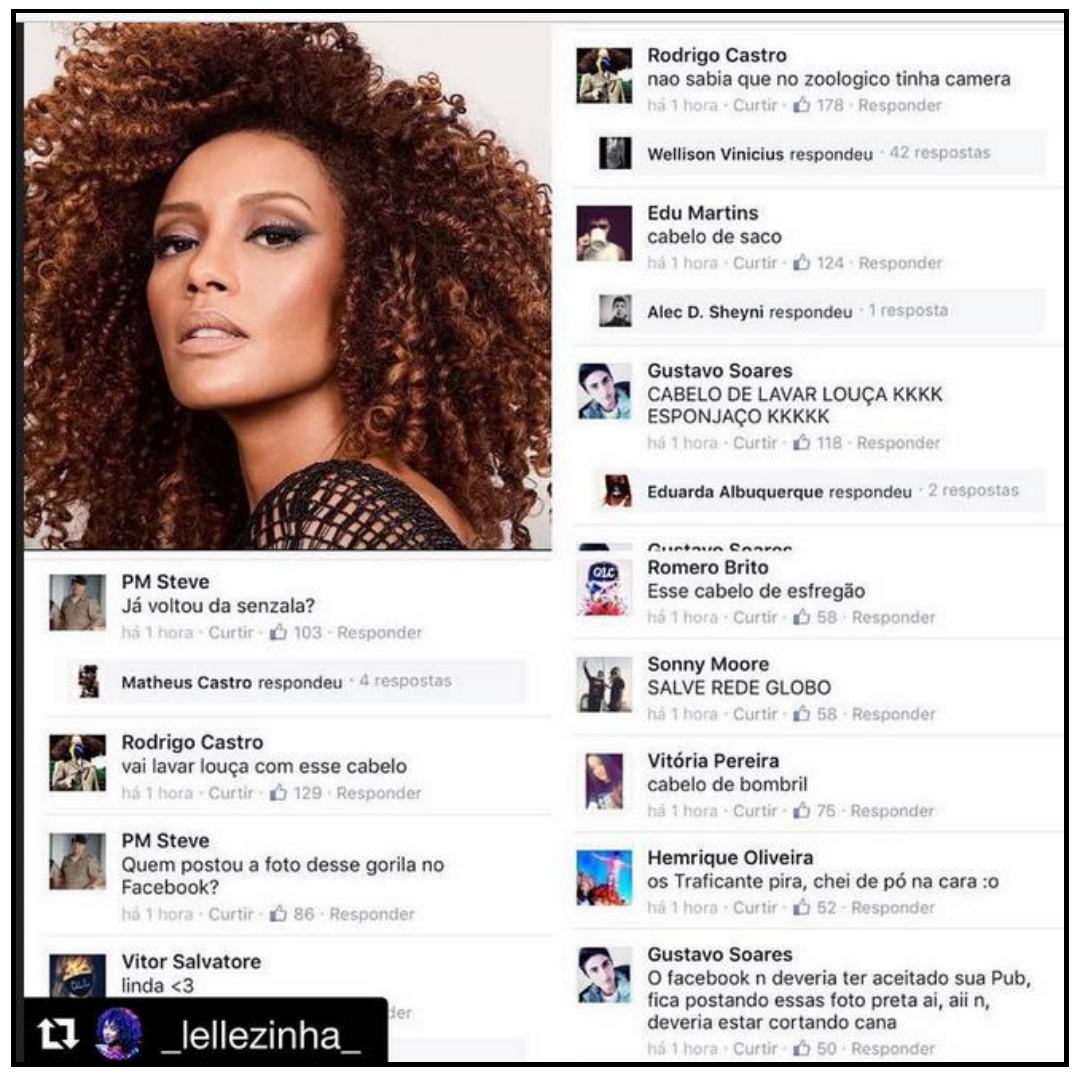

Reprodução do Facebook ${ }^{30}$

29 Fonseca, 2006, p.92.

30 Reprodução do Facebook. Disponível em: http://igcdn-photos-b-a.akamaihd.net/hphotos-akxfal/t51.2885-15/e35/12105220982844901759017 864862593 n.jpg 


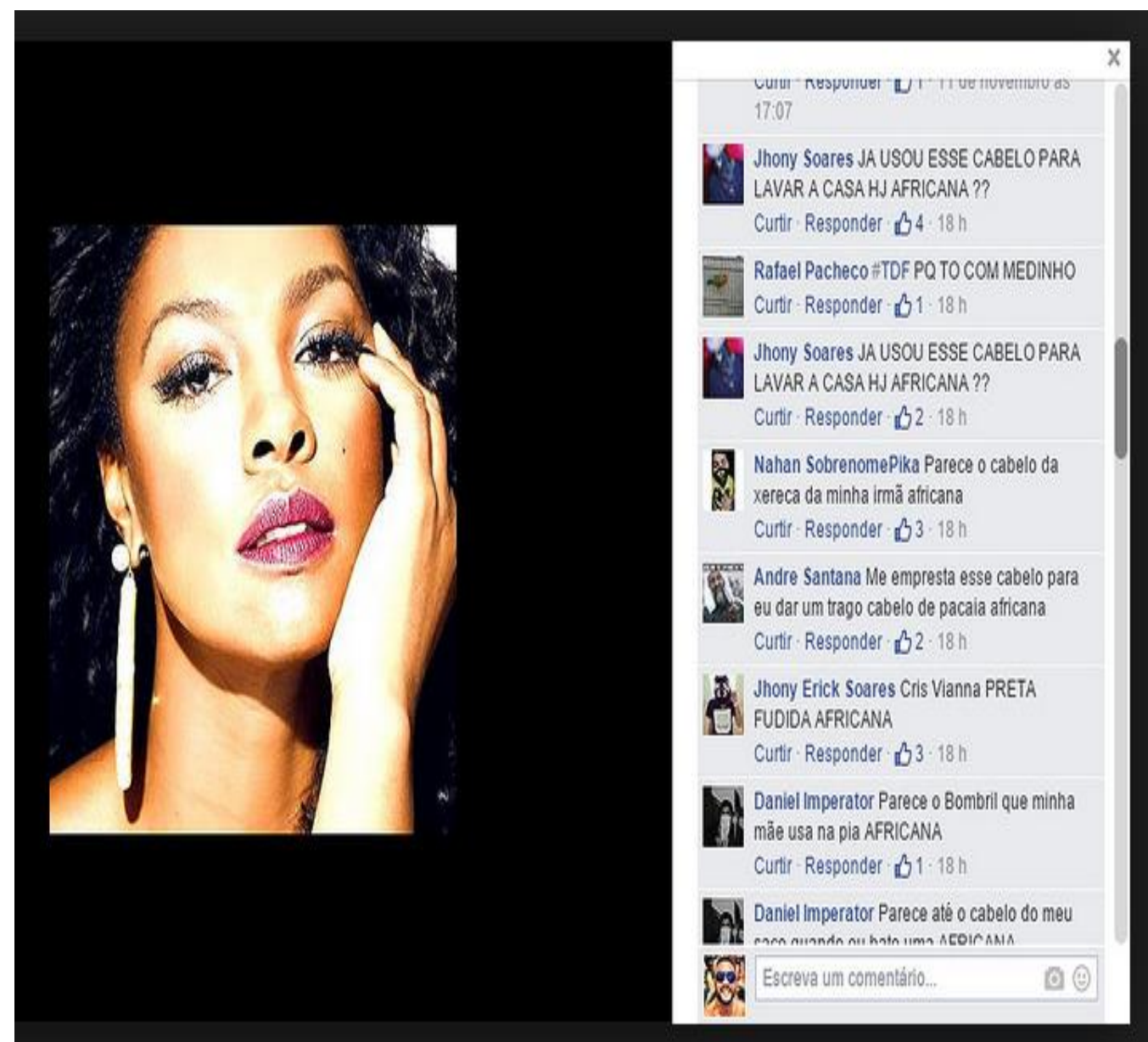

Reprodução do Facebook ${ }^{31}$

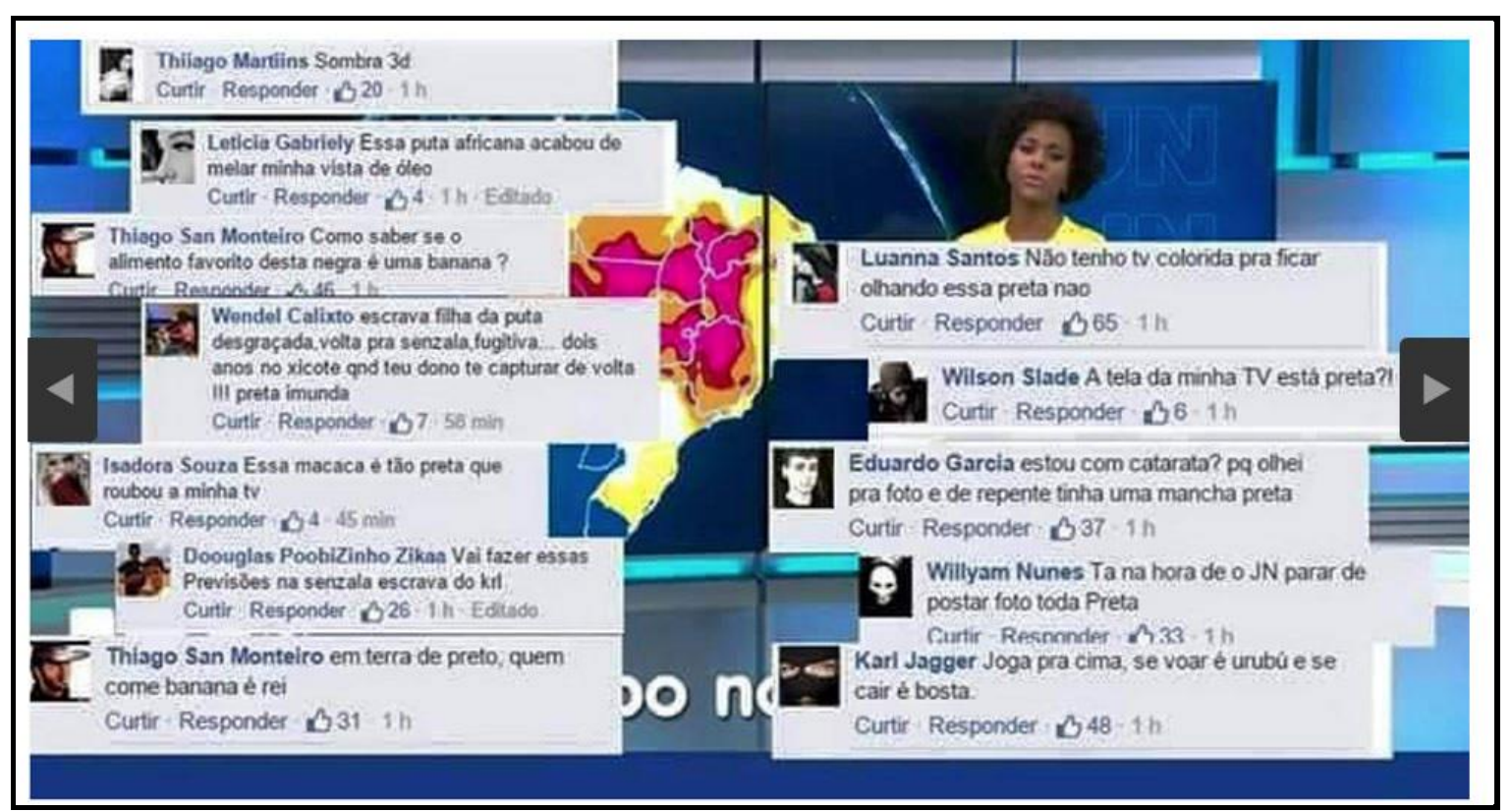

Agressões racistas na página do "Jornal Nacional"32

${ }^{31}$ Reprodução do Facebook. Disponível em:

http://natelinha.vol.com.br/celebridades/2015/1 1/30/depois-de-tais-aravjo-cris-vianna-e-vitimade-racismo-no-facebook-94590.php Acesso em 02/11/2019.

32 Agressões racistas na página do "Jornal Nacional". Disponível em: http://fotografia.folha.vol.com.br/galerias/14669-jornal-nacional\#foto-526579 Acesso em: $02 / 11 / 2019$. 


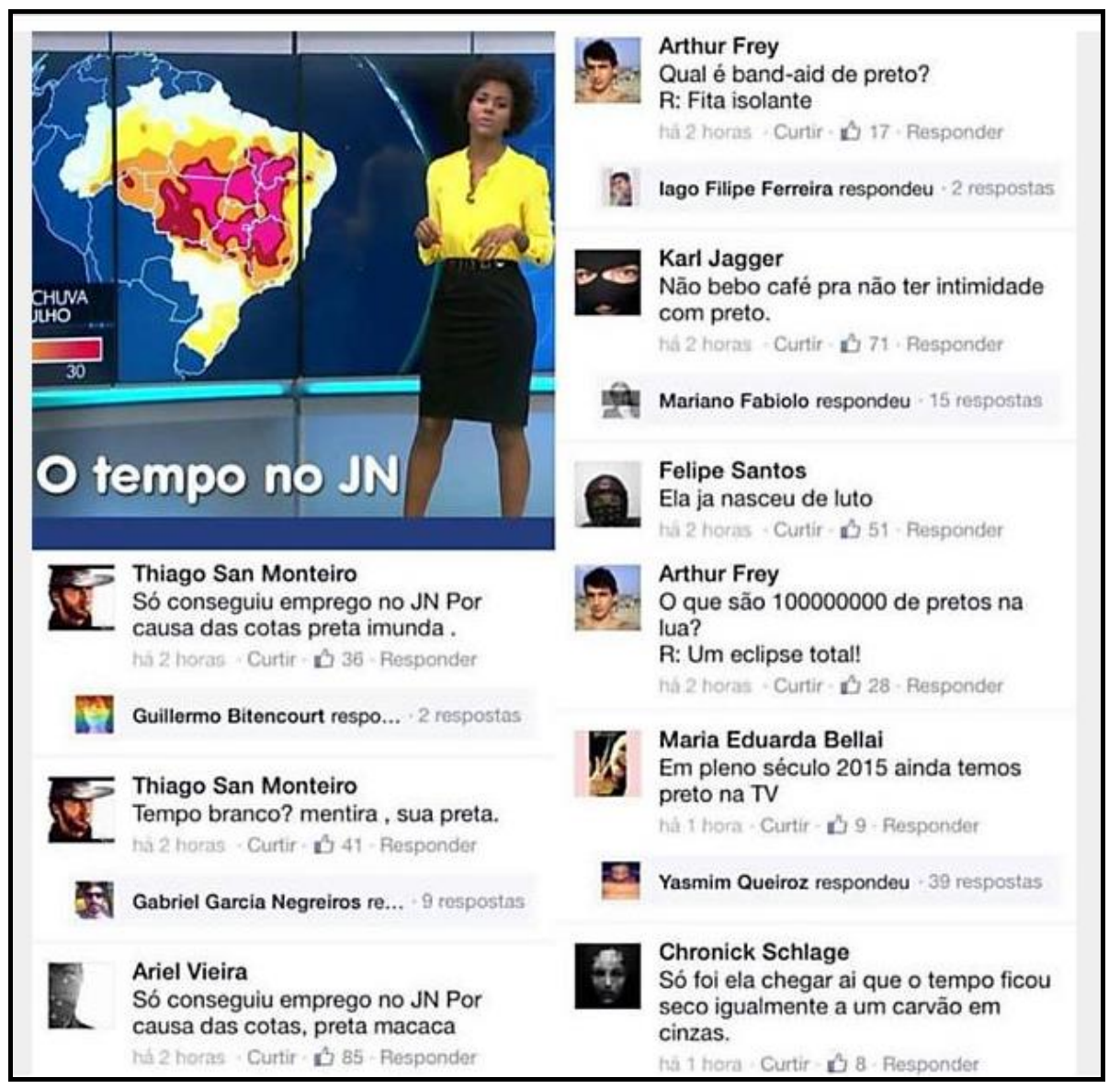

Agressões racistas na página do "Jornal Nacional"33

Agressões racistas dirigidas a mulheres negras, que desafiam o padrão de beleza que é ter a pele branca, os cabelos louros e lisos e os olhos claros. $\bigcirc$ fenótipo negro, com cabelos cacheados ou black power e olhos escuros, afronta ao padrão estético hegemônico, e por este motivo, causam comportamentos e discursos racistas. As agressões destacam a imagem do negro ainda presenta no imaginário da sociedade brasileira: escravo, inferior, incapaz; não adequado ao lugar de destaque, e sendo mulher, considerada objeto sexual.

A não aceitação de uma identidade negra positiva e que merece ser desqualificada, destratada, agredida. O fato de ser negro é considerado um motivo que justifica as agressões. Agressões também dirigidas a uma outra mulher negra, a médica e cantora Julia Rocha, também em rede social e que tratavam negativamente a sua corporeidade negra. Novamente, o fato de estar em uma posição de prestígio (médica) é posta em dúvida, e também críticas ao seu cabelo

33 Agressões racistas na página do "Jornal Nacional". Disponível em: http://fotografia.folha.vol.com.br/galerias/14669-jornal-nacional\#foto-526522 Acesso em: $02 / 11 / 2019$. 
(estilo e coloração). Agressões de raça, gênero e classe.



Reprodução do Facebook ${ }^{34}$

A presença negra em condições de status não é aceita, tampouco seus traços corporais. Não corresponder a um padrão imposto hegemonicamente (branco) parece ser um crime, pelo qual o negro deve ser punido. A assunção da negritude pela hoje majoritária parcela da sociedade brasileira, ao invés de ser um motivo de orgulho, passa a ser justificativa para agressão. E confirma o que diz Fonseca ${ }^{35}$ :

Paradoxalmente, ao ser levada a assumir a sua feição mestiça, a sociedade brasileira continua a fomentar o desejo de se pautar por determinados padrões que, reforçando estereótipos, inscrevem no negro traços e atributos indicadores de uma corporeidade que fascina e horroriza ao mesmo tempo.

Como afirma Souza36 "o negro brasileiro que ascende socialmente não nega uma presumível identidade negra. Enquanto negro, ele não possui uma identidade positiva, a qual possa afirmar ou negar". Souza destaca que ser negro é "criar uma nova consciência que reassegure o respeito às diferenças e que reafirme uma dignidade alheia a qualquer nível de exploração". Reafirme sua humanidade e seus direitos. Souza observa, então, que "assim, ser negro não é uma condição dada, a priori. É um vir a ser. Ser negro é tornar-se negro. (grifos meus). Tornar-se

\footnotetext{
34 Reprodução do Facebook. Disponível em:

http://www.em.com.br/app/noticia/gerais/2016/07/31/interna_gerais,789663/medica-mineira-quecomentou-polemica-da-peleumonia-sofre-ataque-raci.shtml Acesso em 02/11/2019.

35 Fonseca, 2006, p. 92,93.

36 Souza, 1983, p.77.
} 
protagonista de sua própria história, e lutar para transformar sua condição na estrutura social brasileira, sendo negro.

\section{QUILOMBISMO MIDIÁTICO: ESPAÇOS DE EXISTÊNCIA E RESISTÊNCIA NO AMBIENTE VIRTUAL.}

(...) o discurso não é simplesmente aquilo que traduz as lutas ou os sistemas de dominação, mas aquilo por que, pelo que se luta, o poder do qual nos queremos apoderar. (Michel Foucault)

A luta dos negros no Brasil, em busca de uma maior e melhor inserção social, não pode prescindir da sua adequada inserção no espaço midiático. Ações que desenvolvam a discussão de temas relativos à população negra na comunicação social brasileira (como produtores e consumidores, bem como a essência dos conteúdos, imagens e discursos veiculados). Dentre os avanços e desafios que ainda estão presentes na mídia brasileira, Angélica Bahsti, jornalista negra, destaca37:

Temos avançado, hoje já existem novelas onde o negro e a mulher negra já têm papéis de destaque, comerciais onde aparece uma mulher negra ou um homem negro, ainda com problemas, porque os estereótipos ainda estão muito presentes e muito fortes, então a gente ainda precisa fazer muito trabalho para desfazer essa mentalidade e esse pensamento sobre quem é o negro e qual é o papel do negro do País, disse a jornalista.

O ambiente virtual revela-se extremamente útil na luta antirracista. Apesar de ser um ambiente onde inúmeras formas de violência racista prosperam contemporaneamente, é também um espaço de difusão da existência e resistências de discursos negros. Um espaço que permite a proliferação, difusão e articulação de movimentos que buscam desconstruir a estereotipia racista e empoderar a identidade negra, em contraponto à hegemonia da branquitude ${ }^{38}$.

37 O papel da mídia na luta contra o racismo. Disponível em:
http://www.abi.org.br/o-papel-da-midia-na-luta-contra-o-racismo/ Acesso em: 02/10/2019.

38 Branquitude: De acordo com Frankenburg (apud Sovik, 2009, p. 19), a branquitude é "um lugar estrutural de onde o sujeito vê os outros e a si mesmo; uma posição de poder não nomeada, vivenciada em uma geografia social de raça como um lugar confortável e do qual pode atribuir ao outro aquilo que não atribui a si mesmo". Sovik $(2009$, p.18) observa que "a supervalorização do branco é um fenômeno mundial, com particular vigência em lugares que foram colonizados por europeus que implantaram a escravidão. A branquitude, na visão de críticos estrangeiros, não é uma abordagem teórica, mas um objeto com estruturas internas complexas e medonhas, uma categoria de análise, conjuntos de fenômenos locais complexamente arraigados na trama das relações socioeconômicas, socioculturais e psíquicas (...), um processo, não uma coisa". Sovik (2009, p.22) destaca ainda que "a branquitude não é genética e não só define um lugar de fala. É uma 
Sites, blogs e páginas de redes sociais vêm sendo criadas e se destinam a promover a identidade e corporeidade negra, de modo particular a das mulheres negras. $O$ espaço virtual e as plataformas midiáticas se tornam verdadeiros quilombos, que demonstram a existência da beleza negra, e realizam a resistência aos discursos e imagens negativas sobre negros, veiculados massivamente. Dentre vários exemplos, podemos destacar o site do "Instituto de Mídia Étnica"39, o site "Alma preta" 40 o site "Coletivo Guerrilha" 41 e a "ONG Geledés"42, que desenvolvem uma atuação antirracista por meio do espaço virtual. Divulgam temas e conteúdos voltados aos interesses e necessidades da população negra, bem com denunciam o racismo existente na sociedade brasileira, visibilizando as ocorrências, mas também promovendo reflexões e propondo ações que permitam a mudança.

Existem também outros exemplos de ações desenvolvidas na internet, focadas no empoderamento e valorização das mulheres negras. Neste sentido, podemos citar a "ONG Criola"43, o site "Blogueiras negras" 44 além de páginas das

questão de imagem e, portanto, tem como um de seus principais campos de observação os meios de comunicação".

39 O Instituto de Mídia Étnica é uma organização da sociedade civil que realiza projetos para assegurar o direito humano à comunicação e o uso das ferramentas tecnológicas pelos grupos socialmente excluídos, especialmente a comunidade afro-brasileira. Disponível em: http://www.midiaetnica.com.br/ Acesso em: 02/102019.

40 Site Alma preta. A apresentação do site afirma que "a existência de um veículo de imprensa negra e livre expõe a contradição da narrativa do cotidiano, impregnada de um discurso que exclui ou deturpa a identidade do negro. O Brasil é um país formado desde sua gênese por negros (pretos e pardos). Sua imprensa, no entanto, é majoritariamente branca e de constituição racista. A imprensa brasileira de amplo alcance sempre foi controlada pela elite, e representa seu discurso, bandeiras e projeto de Brasil. Uma visão distorcida pelo racismo, pelo machismo e pelo classismo. Expor esta contradição é papel ético da imprensa. Desmontar essa narrativa é missão do Alma Preta. Reconstruir a identidade negra é um valor compartilhado pela negritude brasileira. Apontar um projeto inclusivo e abrangente de nação sempre foi compromisso da mídia negra". Disponível em: http://almapreta.com/sobre/ Acesso em: 02/10/2019.

${ }^{41}$ COLETIVO GUERRILHA. Guerrilha [GRR] é um coletivo de mídia independente que acredita na comunicação livre como instrumento de empoderamento e resistência. Disponível em: http://www.guerrilhagrr.com.br/ Acesso em: 02/10/2019.

42 Geledés. É uma organização da sociedade civil que se posiciona em defesa de mulheres e negros por entender que esses dois segmentos sociais padecem de desvantagens e discriminações no acesso às oportunidades sociais em função do racismo e do sexismo vigentes na sociedade brasileira. Disponível em:

http://www.geledes.org.br/geledes-missao-institucional/ Acesso em: 02/10/2019.

43 CRIOLA. é uma organização da sociedade civil fundada em 1992 E conduzida por mulheres negras. Atuamos na defesa e promoção de direitos das mulheres negras em uma perspectiva integrada e transversal. Disponível em: http://criola.org.br/?page id=257 Acesso em: 02/10//2019

${ }^{44}$ Blogueiras negras. A apresentação do site destaca: "somos mulheres negras e afrodescendentes. Blogueiras com estórias de vida e campos de interesse diversos; reunidas em torno das questões da negritude, do feminismo e da produção de conteúdo. Sujeitas de nossa própria estória e de nossa própria escrita, ferramenta de luta e resistência. Viemos contar nossas estórias, exercício que nos é continuamente negado numa sociedade estruturalmente discriminatória e desigual. Disponível em: 
redes sociais, como a página do facebook denominada "Quando me descobri negra"45. A página pretende refletir sobre "identidade, negritude, racismo. A coletânea "Quando me descobri negra", de Bianca Santana, nos convida a compartilhar nossas próprias histórias". A página é resultado do livro de Bianca Santana Quando me descobri negra, construído a partir de relatos pessoais da autora e de pessoas negras por ela citadas. Os relatos detalham diferentes situações de discriminação racial sofridas, e reflete sobre o processo de assunção da identidade negra pela autora. Neste canal virtual, podem ser ampliadas e discutidas diferentes formas de discriminação, e ações de fortalecimento identitário entre os participantes, para além das páginas impressas do livro. Permite uma escrita e debate contínuos, e promove condições de enfrentamento e luta antirracista. Os depoimentos acabam criando uma rede de apoio e fortalecimento da identidade negra.

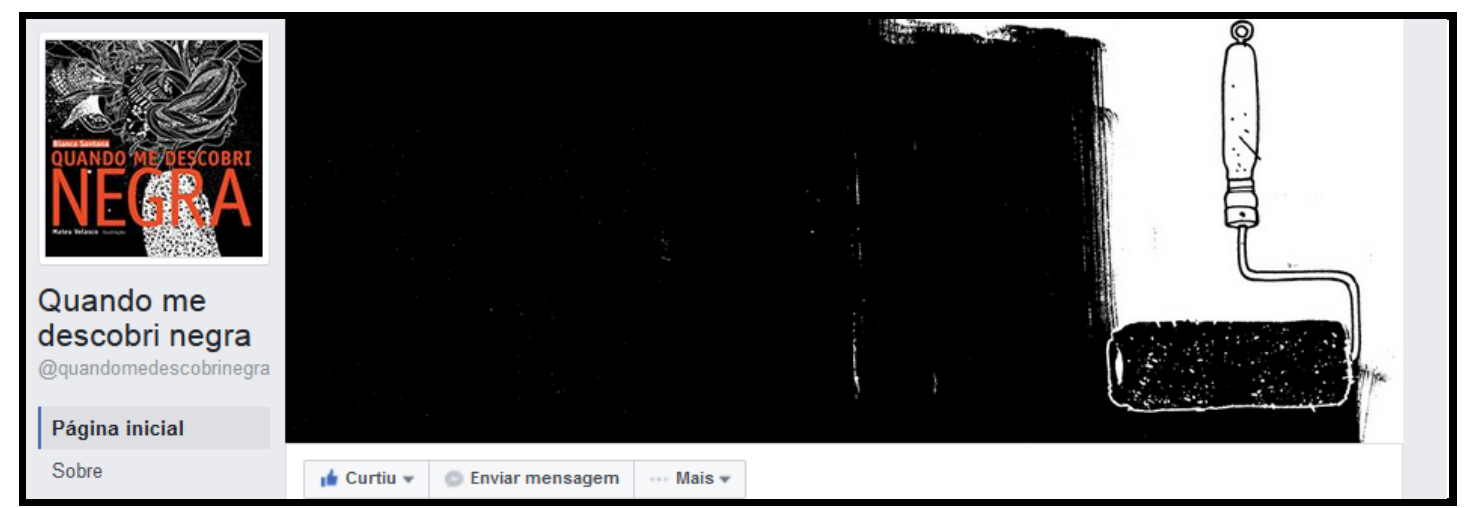

Página do Facebook: Quando me descobri negra

Podemos também destacar o site "Soul Negra"46, que se declara um "site referência especializado em beleza negra. Tudo sobre cabelos, maquiagem para pele negra, noiva negra, looks, dicas de saúde, cuidados com o corpo e muito mais". O manifesto do site destaca que "motivadas por discussões sobre a escassez de referências visuais e informações que representam ou são direcionadas à beleza negra criamos o Soul Negra. Um espaço para nos comunicarmos, aprendermos e disseminarmos informações sobre este universo".

http://blogueirasnegras.org/quem-somos/ 02/10/2019.

45 Quando me descobri negra. Disponível em:

https://www.facebook.com/quandomedescobrinegra/info/? entry point=page nav about item\&t ab=page info Acesso em: 02/10/2019.

46 Site Soul Negra: Manifesto. Disponível em:

http://www.soulnegra.com/manifesto/?utm_source=site\&utm_medium=link\&utm_campaign=map a-rodape Acesso em: 01/11/2019. 
As diferentes estratégias de luta antirracista utilizadas por negros e negras no espaço virtual demonstram a mudança (positiva) na atuação midiática negra para além dos meios e veículos da mídia tradicional. Lutar por visibilidade, desconstrução de discursos e imagens racistas, bem como pelo fortalecimento identitário já são realidade na paisagem midiática brasileira. Batista ${ }^{47}$ destaca que:

Ainda que de maneira muito reduzida, pessoas negras têm ganhado algum espaço nas mídias impressas, televisiva e digitais e tentado com muito esforço apresentar uma outra imagem do que é a negritude. Meninas e rapazes que aceitam e assumem seu fenótipo negro como algo belo, ocupam de forma cada vez mais forte a moda, a fotografia, as artes e a produção cultural em geral. Além disso, cada vez mais projetos, que vão de páginas no Facebook e no Instagram até grandes ensaios fotográficos, compilam e espalham imagens positivas de pessoas negras na internet.

A produção e disseminação de visualidades e estéticas afirmativas da corporeidade negra vem sendo desenvolvida de diferentes formas. Desde a veiculação de imagens negras em sites, blogs e editoriais de moda (nas mídias impressa e virtual), bem como pelas artes plásticas em diferentes espaços e plataformas. Um dos exemplos destas ações é o trabalho de Muha Bazila48, na exposição "Odara"49, que significa "lindo". Como descrito no site "O artista encontrou na série uma oportunidade de valorizar e reafirmar a estética da mulher negra, partindo para caminhos que fogem da reprodução de estereótipos e da hipersexualização". Na apresentação da série, destaca que "apesar da persistente negação do racismo, muitas pessoas se incomodam com o fato de a série retratar somente mulheres negras". Revela uma beleza negra, estabelecendo um novo padrão frente à cultura visual racista sobre o corpo e estética negra.



\footnotetext{
47 Batista, 2016.

48 Muha Bazila: Biografia. Disponível em: http://www.muhabazila.com/bio/ Acesso em: 01/1 1/2019.

49 Odara: http://www.muhabazila.com/odara-1/
} 

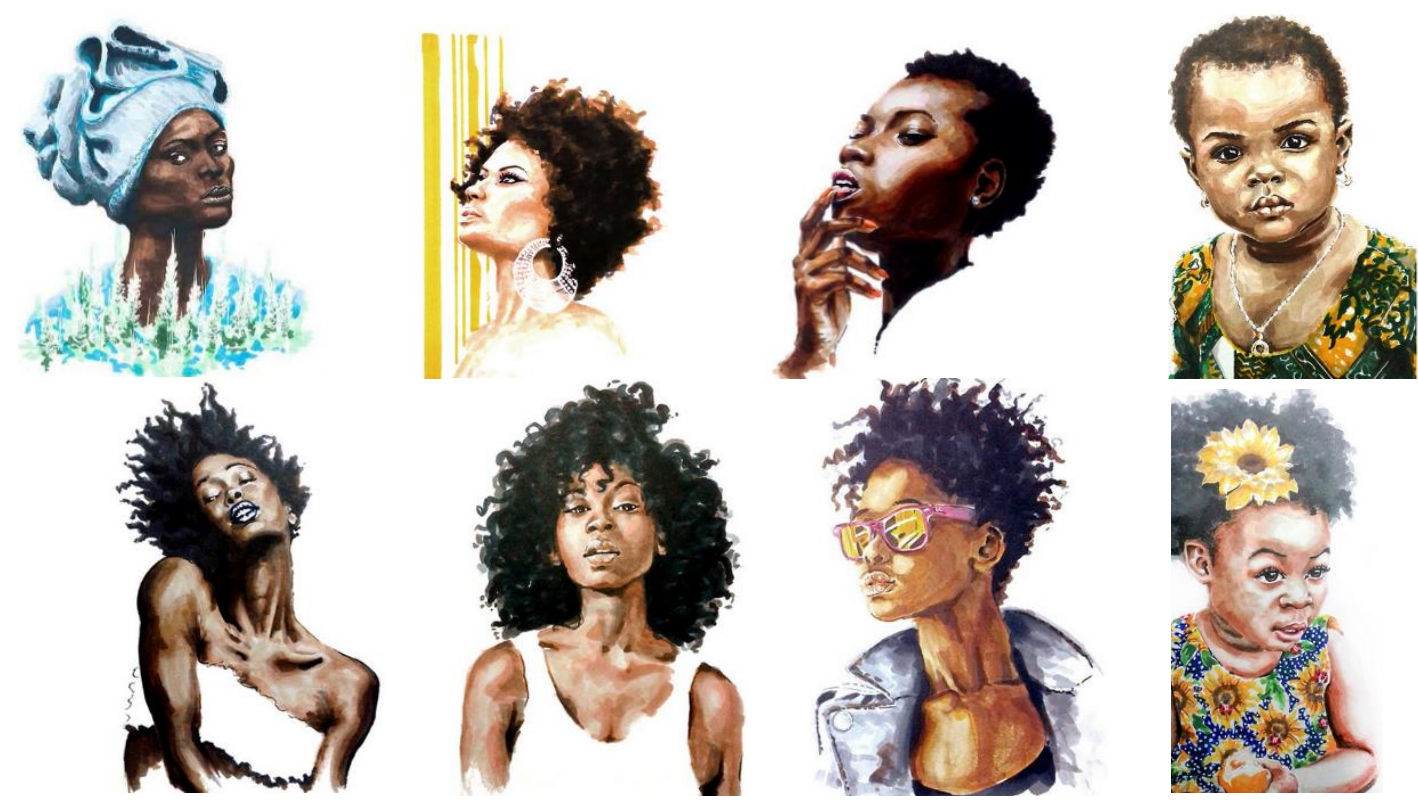

Mulheres negras, de diferentes tons de pele, cortes e estilos de cabelo, contextos e vestimentas, de diferentes faixas etária, retratadas de modo singular, cotidiano, e belo (Odara). Visualidades afirmativas e que (re)constroem um novo imaginário de beleza feminina negra. Bazila teve suas imagens utilizadas no especial "(In)consciência negra"50, veiculado pelo portal Metrópoles" que tratava da questão do racismo na cidade de Brasília (DF), capital do país. O artista afirma: "vi no retrato das mulheres negras uma forma de afirmar a estética negra e questionar padrões eurocêntricos". As imagens desconstroem o modelo, hegemônico e eurocêntrico, e desenvolve uma ação antirracista. E demonstram a importância do resgate de uma ancestralidade negra, e construção de uma consciência racial positiva sobre a identidade negra.

\section{AÇÕES DE E-AFIRMAÇÃO E DESCONSTRUÇÃO DO EPISTEMICÍDIO E DA ESTEREOTIPIA RACISTA.}

A luta por reconhecimento, por parte dos negros no Brasil, é contínua e não é recente. Borges"51 afirma que "o discurso do reconhecimento é obra da aventura moderna, e a reivindicação de novos/outros regimes de representação/visibilidade destinados a grupos historicamente discriminados é fenômeno cuja fisionomia deita raízes desde o início do século XX". Quando

50 (In)consciência negra: os contornos do racismo na cidade de linhas retas. Disponível em: http://www.metropoles.com/materias-especiais/consciencia-negra/\#

51 Borges, 2016. 
diversas manifestações racistas são retratadas em diferentes contextos e espaços globais, percebe-se como é necessário intensificar o debate sobre o racismo. van Dijk52 destaca que "se o racismo não se tornar um assunto público pelo discurso público dos grupos étnico-raciais minoritários, a dominação étnica continuará inalterada".

A sutileza da presença do racismo, e as suas consequências nas estruturas sociais, impacta até mesmo as iniciativas que buscam promover a mudança nas formas de produção de conhecimento qualificado e instrumentalização conceitual da luta antirracista. Podemos exemplificar analisando a iniciativa da Universidade Federal da Grande Dourados (UFGD), em parceria com a UNESCO, que desenvolveram o Dicionário Crítico de Gênero e publicaram a sua 2a . Edição em 2019. Em sua apresentação os organizadores53 afirmam: o "Dicionário Crítico de Gênero" partiu do entendimento que era necessário reunir numa obra o conjunto de vocábulos de referencial crítico, assim como aqueles termos que permitem um tratamento problematizador do universo dos estudos de gênero, mulheres, masculinidades e sexualidades". A obra, em suas 748 páginas, abarca um expressivo conjunto de verbetes a respeito da temática de gênero. Entretanto, dentre os verbetes presentes, percebemos a ausência do verbete "mulheres negras". No dicionário estão descritos os verbetes "Mujeres Árabes" (p. 527), "Mulher e Guerra" (p. 532), Mulheres indígenas, mulheres ameríndias" (p. 536), "Mulheres Judias" (p. 540), "Mulheres Migrantes" (p. 545), "Mulheres Surdas" (p. 550).

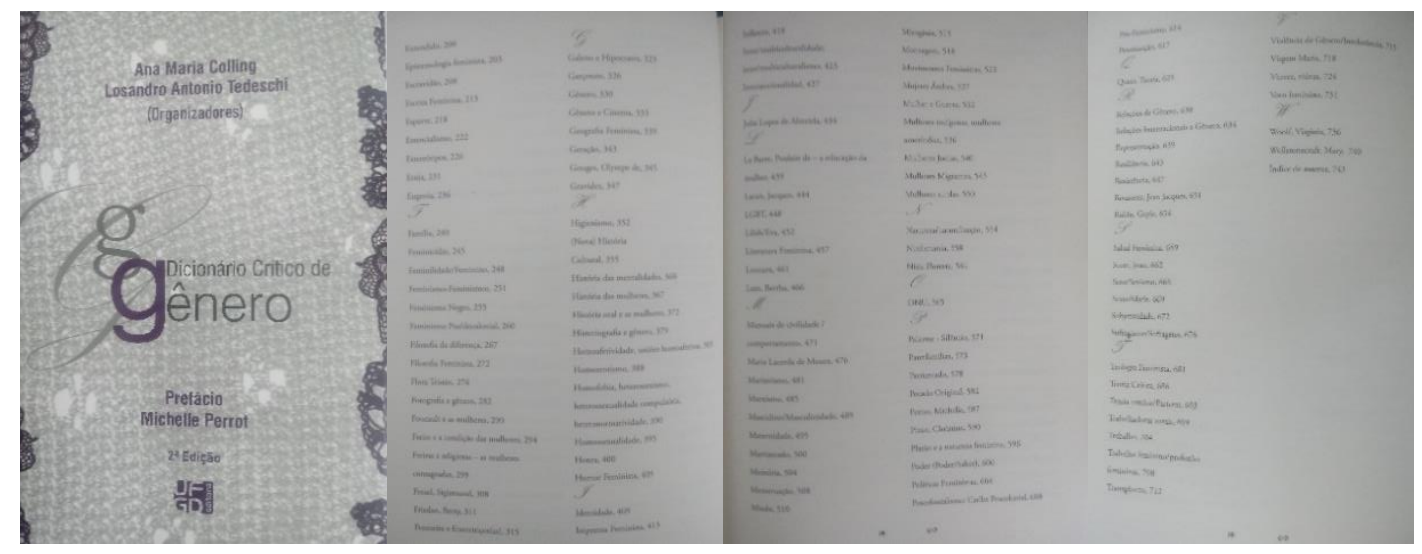

Foto: Dicionário crítico de gênero, capa, p. 8,9,10.

Cabe registrar a presença no dicionário do verbete "Feminismo Negro" (p.

52 van Dijk, 2008, p. 16.

53 Colling e Tedeschi, 2019, p.17 
255). No texto do referido verbete (p. 258, 259) está expresso:

(...) atualmente, diversos grupos que levam avante a bandeira do feminismo negro têm encontrado na internet um importante espaço para o exercício de sua militância. (...) Somos mulheres negras e afrodescendentes. Blogueiras com estórias de vida e campos de interesses diversos.; reunidas em torno das questões de negritude, do feminismo, e da produção de conteúdo. Viemos contar nossas estórias, exercício que nos é continuamente negado numa sociedade estruturalmente discriminatória e desigual.

Percebemos também no dicionário a ausência do verbete "racismo". Racismo que fundamenta as desigualdades presentes nas estruturas, instituições, imáginário, discursos. Racismo que compromete o acesso à cidadania aos negros e negras brasileiros. Racismo que mantém sua influ encia inclusive na (re)produção de paradigmas e epistemologias.

O desenvolvimento de novas formas de luta antirracista é urgente, prioritária, e deve ser empreendida de diferentes formas em todas as áreas da vida social, inclusive na na esfera midiática. "Arriscaria dizer que a nossa época está sendo marcada por embates na ordem do imaginário, por guerra de imagens e signos, por sede de representação e visibilidade" afirma Borges54; e destaca que "signos emergentes/insurgentes rebatem signos "estáveis", enrijecidos, carcomidos por visibilidades que não cabem mais nos estereótipos de outrora".

A atual ofensiva dos negros pela ocupação de espaços na mídia, de acordo com a pesquisadora, representa "uma trincheira cada vez mais compacta, constituída em sua maioria por jovens, e transborda os espaços materiais e digitais em reação as essas imagens calcificadas". Borges 55 afirma ainda que "política, representação e imaginário formam um tripé incontornável"; e "que a conquista do poder passa necessariamente por agenciamento de imagens, por visibilidades (...). Desconstruir uma histórica estrutura de discursos e imagens racistas, e (re)construir uma visibilidade e representação discursiva afirmativa têm sido promovidos intensamente de modo a permitir o fortalecimento da identidade negra. Fortalecimento identitário, que permitirá a melhoria de sua condição na estrutura desigual da sociedade brasileira, favorecendo a conscientização sobre a ampliação de sua inserção em melhores espaços de poder e respeito aos seus

\footnotetext{
54 Borges, 2016.

55 Idem, Ibidem.
} 
direitos historicamente negados em virtude do racismo.

Torna-se fundamental reescrever (ou repensar) novas formas de presença na realidade social, por parte da população negra; propor uma nova escrita e visualidades, para a participação do negro em novos papéis. Tal situação pode ser verificada no ensaio de Loras 56 "o mundo real, só que ao contrário", onde a autora faz a seguinte proposta:

Tente imaginar um mundo diferente. Nesse mundo, tudo que foi feito pelos negros é considerado inteligente, lindo e incrível e todas as referências históricas são com negros. Um mundo onde os grandes personagens da história são todos negros. Os revolucionários, os historiadores, filósofos, inventores, escritores e até Deus, o ser supremo, é representado como negro e, claro, Jesus Cristo também. Quando as crianças assistem televisão, nos desenhos animados, a maioria dos personagens são negros, assim como os príncipes e as princesas. Nas novelas, a mulher branca é sempre a faxineira, ou a amante do homem negro e rico. E a única coisa que sabemos sobre os brancos, são duas páginas nos livros didáticos que dizem que o branco foi escravizado. (grifos meus)

Imaginar a identidade negra como valorizada, positiva, privilegiada. Um imaginário isento de preconceito. Uma imagem empoderada dos negros. Desvelar, revelar, promover a difusão das vozes das mulheres negras, em diferentes linguagens, em todos os espaços e níveis da vida nacional.

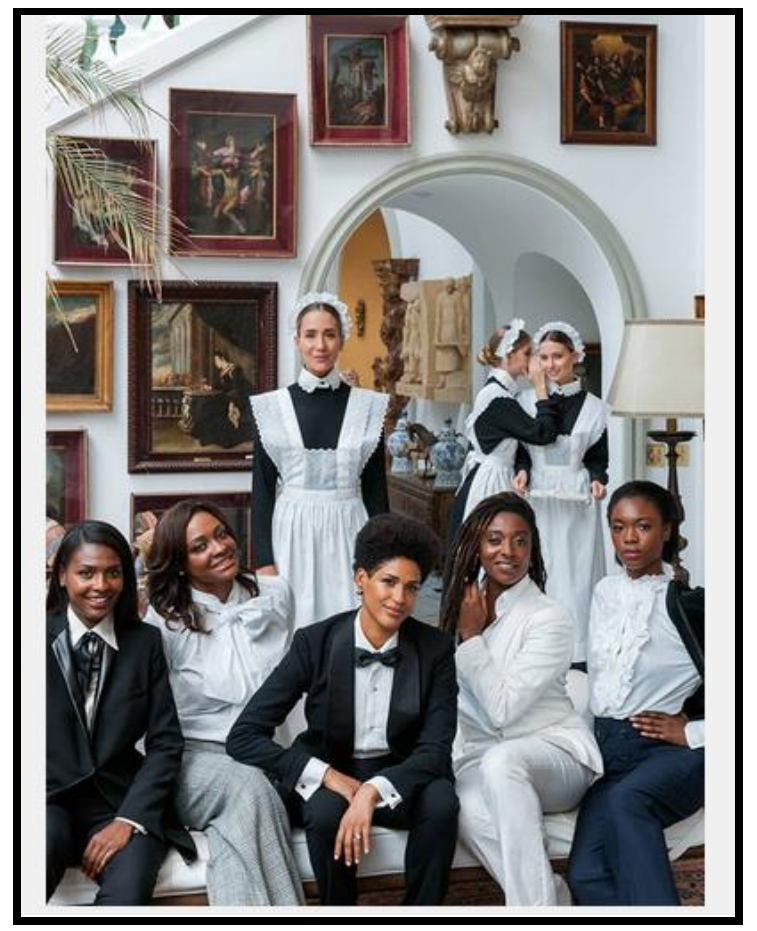

FIGURA 457

\footnotetext{
56 Loras, 2016.

57 FIGURA 4. Disponível em: https://www.nexojornal.com.br/ensaio/2016/O-mundo-real-s\%C3\%B3que-ao-contr\%C3\%Alrio
} 
Além da proposta discursiva, o ensaio apresenta uma provocação visual, onde mulheres negras ocupam uma posição de status, e as mulheres brancas de subalternidade. Loras58 descreve: "a fotografia representa um ambiente aristocrático, porém com negras representando pessoas da elite, enquanto as mulheres brancas estão uniformizadas como empregadas, sendo uma delas a princesa Paola de Orleans e Bragança". A intenção do ensaio, segundo Loras, é "gerar uma reflexão sobre o tema, provocar o debate e gerar discussão". E faz a seguinte proposição: "minha pergunta aos brancos é: você trocaria seu lugar para ser negro em nossa sociedade, com todas as consequências que ser a negro ainda representa em 2016? Qual seria a resposta dos brancos a este questionamento? Neste sentido, cabe refletir na declaração de Nascimento59:

As narrativas sobre o pensamento das mulheres negras vão além das expectativas comuns sobre a sua produção escrita. A população negra, em particular, e a sociedade brasileira, no geral, perderam quando não foram influenciadas por tais pensamentos e quando os mesmos não ocuparam as estantes das bibliotecas das universidades, das escolas públicas, das livrarias. Certamente, esses olhares contribuiriam para se pensar uma nação mais igual, justa e sintonizada com as suas especificidades.

O empoderamento do negro nas mídias pode promover uma nova visão dos brancos sobre "o ser negro". O empoderamento do negro na mídia pode favorecer a desalienação identitária, e acarretar a assunção de uma negritude positiva por parte dos negros. O empoderamento negro deve reescrever discursos e imagens sobre uma ancestralidade africana e construir um orgulho de nossa afrobrasilidade. Ocupar o espaço midiático, desconstruindo epistemologias racistas e (re)construindo nossa história com conhecimentos, valores e saberes que valorizem a nossa negritude.

(Re)existir para existir!

\footnotetext{
58 Loras, 2016.

59 Nascimento, 2018, p. 204.
} 


\section{REFERÊNCIAS:}

ALMADA, Sandra. Estética: a revolução política dos negros. Revista Raça Brasil, edição 141, Fevereiro de 2010.

BATISTA, Robin. Estética negra empodera, sim. Porque não dá para enfrentar o racismo quando você ainda se odeia. Disponível em:

http://www.guerrilhagrr.com.br/estetica-negra-empodera-sim-porque-nao-dapara-enfrentar-o-racismo-quando-voce-ainda-se-odeia/ Acesso em 04/1 1/2019.

BORGES, Rosane. Mídia, racismos e representações do outro: ligeiras reflexões em torno da imagem da mulher negra. In, BORGES, Roberto Carlos da Silva; BORGES, Rosane (Orgs.). Mídia e racismo. Petrópolis, RJ: DP ET Alii; Brasília, DF: ABPN, 2012.

BORGES, Roberto Carlos da Silva; BORGES, Rosane (Orgs.). Mídia e racismo. Petrópolis, RJ DP ET Alii; Brasília, DF : ABPN, 2012.

CHIZIANE, Paulina. Eu, mulher... por uma nova visão de mundo. Belo Horizonte: Nandyala, 2018.

COLLING, Ana Maria; TEDESCHI, Losandro antônio. Dicionário crítico de gênero. Dourados, MS: Ed. Universidade Federal da Grande Dourados, 2019.

CRISTALDO, Heloisa. Latinidades: valorização da estética negra feminina é resistência ao racismo. Disponível em:

http://agenciabrasil.ebc.com.br/geral/noticia/2016-07/latinidades-valorizacaoda-estetica-negra-feminina-e-resistencia-ao-racismo. Acesso em: 02/10/2019.

FONSECA, Maria Nazareth Soares. Visibilidade e ocultação da diferença: imagens de negro na cultura brasileira. In, Brasil afro-brasileiro. Belo Horizonte: Autêntica, 2006.

FOUCAULT, Michel. A ordem do discurso. São Paulo: Edições Loyola, 2008

HALL, Stuart. A identidade cultural na pós-modernidade. Rio de Janeiro: DP\&A, 2006.

KELLNER, Douglas. A Cultura da mídia - estudos culturais: identidade e política entre 
o moderno e o pós-moderno. Bauru, S.P.: EDUSC, 2001.

LORAS, Alexandra Baldeh. O mundo real, só que ao contrário. Nexo Jornal, 2016. Disponivel em: https://www.nexojornal.com.br/ensaio/2016/O-mundo-reals\%C3\%B3-que-ao-contr\%C3\%A1rio. Acesso em: 04/11/2019.

MENEGHEL, Stela Nazareth; FARINA, Olga; RAMAO, Silvia Regina. Histórias de resistência de mulheres negras. Rev. Estudos Feministas, Florianópolis, v. 13, n. 3, p. 567-583, Dec. 2005 Disponível em:

http://www.scielo.br/scielo.php?script=sci_arttext\&pid=S0104-

026X2005000300006\&lng=en\&nrm=iso\&tlng=pt Acesso em: 02/10/2019.

PEREIRA, Edimilson de Almeida; GOMES, Núbia Pereira de Magalhães. Ardis da imagem: exclusão étnica e violência nos discursos da cultura brasileira. Belo Horizonte: Mazza Edições, Editora PUCMinas, 2001.

RAMOS, Silvia. Mídia e Racismo. Rio de Janeiro: Pallas, 2002

RODRIGUES, Carla. Mulher, conceito plural. Site OUTRASPALAVRAS, 2016. Disponível em: https://outraspalavras.net/sem-categoria/mulher-conceito-plural/. Acesso em: 02/10/2019.

ROSA, Ana Beatriz. Por que o termo mulata ainda é usado em pleno 2019 para se referir a mulheres negras. Disponível em:

https://www.huffpostbrasil.com/entry/carnaval-racismo-

mulata br 5c7a9350e4b0e5e313cace5a?utm hp ref=br-mulher-negra. Acesso em: 02/10/2019.

SAMPAIO, Cristiane. Os meios tradicionais massacram a nossa identidade negra. Disponível em:

https://www.brasildefato.com.br/2016/07/27/os-meios-tradicionais-massacram-anossa-identidade-negra-diz-apresentadora/ Acesso em 27/07/2019.

SANTOS, Jorge Luís Rodrigues dos. A revista "Raça Brasil": uma proposta de imprensa negra na mídia brasileira do século XXI? Tese de Doutorado em Memória Social. Programa de Pós-graduação em Memória Social da UNIRIO (PPGMS/UNIRIO: Rio de Janeiro, 2017. 
SCOTT, Joan. Gênero: uma categoria útil de análise histórica. Educação e Realidade, Porto Alegre, v. 16, n. 2, p. 5-22, 1990.

SILVA, Joselina. O pensamento de/por mulheres negras. Belo Horizonte: Nandyala, 2018.

SOUZA, Neusa Santos. Tornar-se negro: as vicissitudes da identidade do negro brasileiro em ascensão social. Rio de Janeiro; Editora Graal, 1983.

TAVARES, Júlio Cesar de Souza e FREITAS, Ricardo Oliveira de. Mídia e racismo: colonialidade e resquícios do colonialismo, In, Racismos: olhares plurais. Salvador: EdUFBA, 2010 .

TRUTH, Sojourner. Eu não sou uma mulher? E outros discursos. Belo Horizonte: Nandyala, 2019

VAN DIJK, Teun A. Racismo e discurso na América Latina. São Paulo: Contexto, 2008. VIEIRA, Andréa Lopes da Costa; GOMES, Edlaine Campos. Novos contextos, antigas questões em memória. In, DODEBEI, Vera; FARIAS, Francisco R. de; GONDAR, Jô. Por que memória social? Rio de Janeiro: Híbrida, 2016.

Jorge Luís Rodrigues dos Santos: Doutor em Memória Social (UNIRIO), Mestre em Educação (UNIRIO). Graduado em Letras. Professor da SEEDUC/RJ (Português e Literatura, habilitado em Sociologia e Filosofia). Atuação em docência na educação básica e superior (nas esferas pública e privada), como Professor Formador em Projetos da SEEDUC/RJ, CAPES/MEC e Tutor do Sistema UAB e Fundação CECIERJ.

Tatiana Costa de Souza Pereira: Historiadora, graduanda em Letras e professora da Secretaria Municipal de Educação de Macaé.

(c) (7) This work is licensed under a Creative Commons Attribution 4.0 International License. (c) (1) Este trabalho está licenciado sob uma Licença Creative Commons - Atribuição 4.0 Internacional.

Artigo recebido para publicação em: 23 de outubro de 2020.

Artigo aprovado para publicação em: 25 de dezembro de 2020. 